\title{
Resveratrol promotes myogenesis and hypertrophy in murine myoblasts
}

\author{
Anna Montesano ${ }^{1}$, Livio Luzi ${ }^{1,2}$, Pamela Senesi ${ }^{1,2}$, Nausicaa Mazzocchi ${ }^{3}$ and Ileana Terruzzi ${ }^{3{ }^{*}}$
}

\begin{abstract}
Background: Nutrigenomics elucidate the ability of bioactive food components to influence gene expression, protein synthesis, degradation and post-translational modifications.

Resveratrol (RSV), natural polyphenol found in grapes and in other fruits, has a plethora of health benefits in a variety of human diseases: cardio- and neuroprotection, immune regulation, cancer chemoprevention, DNA repair, prevention of mitochondrial disorder, avoidance of obesity-related diseases. In skeletal muscle, RSV acts on protein catabolism and muscle function, conferring resistance against oxidative stress, injury and cell death, but its action mechanisms and protein targets in myogenesis process are not completely known. Myogenesis is a dynamic multistep process regulated by Myogenic Regulator Factors (MRFs), responsible of the commitment of myogenic cell into skeletal muscle: mononucleated undifferentiated myoblasts break free from cell cycle, elongate and fuse to form multinucleated myotubes. Skeletal muscle hypertrophy can be defined as a result of an increase in the size of pre-existing skeletal muscle fibers accompanied by increased protein synthesis, mainly regulated by Insulin Like Growth Factor 1 (IGF-1), PI3-K/AKT signaling pathways.

Aim of this work was the study of RSV effects on proliferation, differentiation process and hypertrophy in C2C12 murine cells.
\end{abstract}

Methods: To study proliferative phase, cells were incubated in growth medium with/without RSV (0.1 or $25 \mu \mathrm{M})$ until reaching sub confluence condition $(24,48,72$ h). To examine differentiation, at $70 \%$ confluence, cells were transferred in differentiation medium both with/without RSV (0.1 or $25 \mu \mathrm{M})$ for $24,48,72,96$ hours. After 72 hours of differentiation, the genesis of hypertrophy in neo-formed myotubes was analyzed.

Results: Data showed that RSV regulates cell cycle exit and induces C2C12 muscle differentiation. Furthermore, RSV might control MRFs and muscle-specific proteins synthesis. In late differentiation, RSV has positive effects on hypertrophy: RSV stimulates IGF-1 signaling pathway, in particular AKT and ERK 1/2 protein activation, AMPK protein level and induces hypertrophic morphological changes in neo-formed myotubes modulating cytoskeletal proteins expression.

Conclusions: RSV might control cell cycle promoting myogenesis and hypertrophy in vitro, opening a novel field of application of RSV in clinical conditions characterized by chronic functional and morphological muscle impairment.

Keywords: Resveratrol, Proliferation, Myoblast, Differentiation, Myocyte, Myogenic Regulatory Factors, Myotube, Hypertrophy

\footnotetext{
* Correspondence: terruzzi.ileana@hsr.it

${ }^{3}$ Division of Metabolic and Cardiovascular Sciences, Metabolism,

Nutrigenomics and Cellular Differentiation Unit, DIBIT-San Raffaele Scientific

Institute, Milan, Italy

Full list of author information is available at the end of the article
} 


\section{Background}

Skeletal muscle differentiation

Skeletal muscle differentiation is a dynamic multistep process that involves two simultaneous phenomena. The first is the induction of muscle-specific genes expression by Myogenic Regulatory Factors (MRFs), such as Myf-5, MyoD, Myf-6 and Myogenin [1-8] (Figure 1A).

The second phase is the commitment of myogenic cells into skeletal muscle cells: mononucleated undifferentiated myoblasts break free from the cell cycle, cease to divide, elongate and fuse into multinucleated myotubes [1-3,9-12] (Figure 1A). A differentiation marker in neo-formed myotubes is the transcription induction of structural muscle-specific genes, such as Myosin Heavy Chain $(\mathrm{MyHC})$, the major structural protein in myotubes [9-11].

At the molecular level, several positive and negative cell cycle regulators have been identified. Progression through cell cycle phases is dependent on consecutive activation and inhibition of phosphoproteins by cyclindependent kinases (CDKs) complexed with their activators cyclins $[1,4,5,13]$.

Furthermore, cytoskeletal reorganization occurs before and after myoblast fusion: a number of studies indicate that
$\mathrm{N}$-Cadherin (N-cad), a member of calcium-dependent cell adhesion molecules, and Alpha-Sarcomeric Actinin ( $\alpha$-act), an actin binding protein, have a central role in these cytoskeletal reorganizations $[14,15]$.

Further, AMP-activated protein kinase (AMPK) appears to act as a master regulator of skeletal muscle metabolism and as a negative feedback control to maintain muscle hypertrophy [16].

When the cellular AMP/ATP ratio is high, AMPK is activated, inhibiting ATP-consuming anabolic pathways and promoting ATP-producing catabolic pathways: as result protein synthesis and cell growth are suppressed [16-18].

\section{Muscle hypertrophy}

Skeletal muscle is a dynamic tissue that can either increase or decrease its mass in response to a variety of environmental causes such as exercise, nutrients and starvation.

Two major signaling pathways have been identified that control these processes through two distinct positive and negative mechanisms respectively, mediated by either Insulin Like Growth Factor 1 (IGF-1) or Growth and Differentiation Factor (GDF8), otherwise known as Myostatin [19,20].

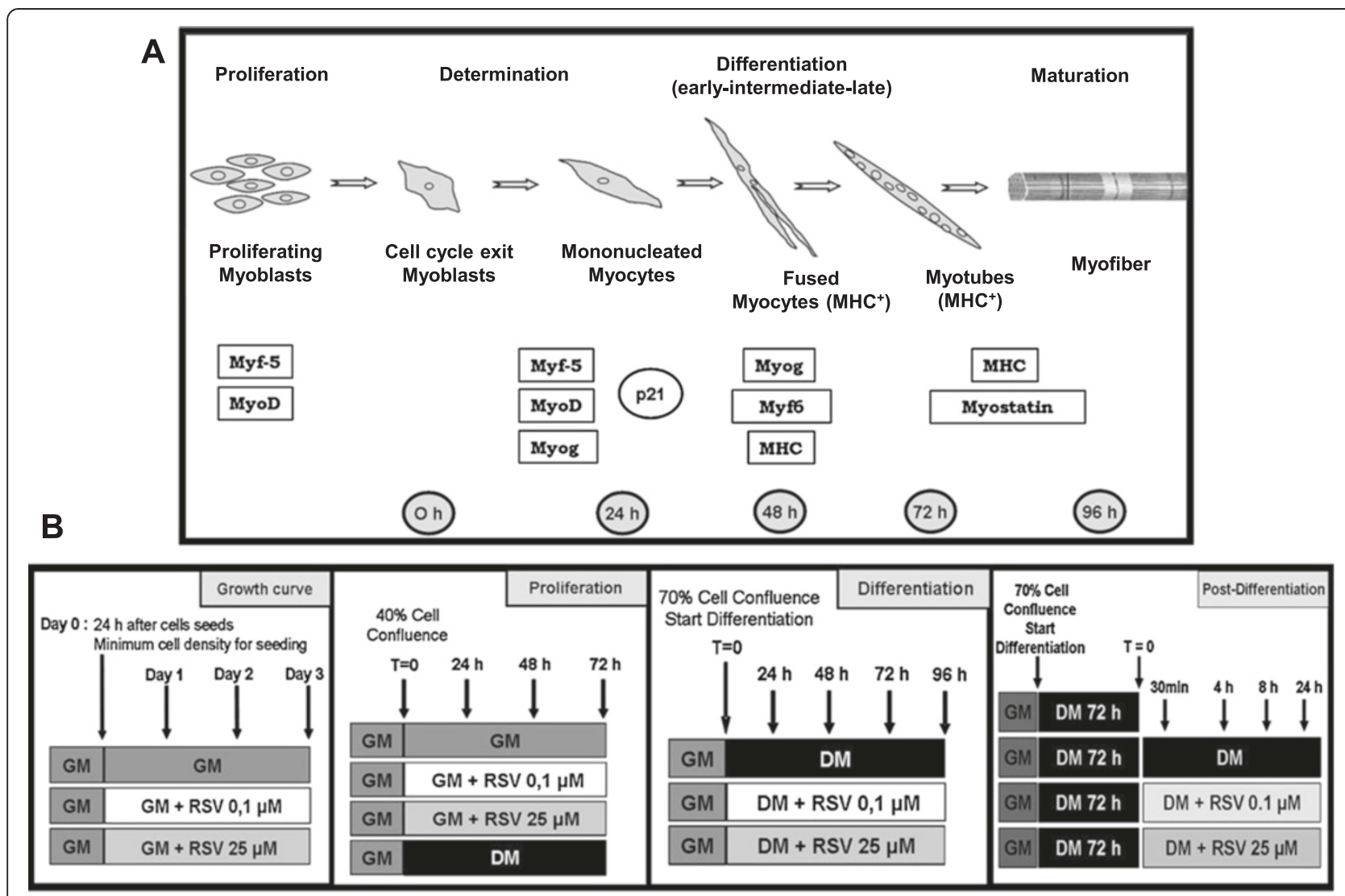

Figure 1 Stages of myogenesis and experimental study design. A) Schematic illustration of skeletal muscle differentiation. B) Description of each experimental phase of the study protocol. 
Skeletal muscle hypertrophy can be defined as an overall increase of muscle mass, as a result of an enlargement of the size of pre-existing skeletal muscle fibers accompanied by enhanced protein synthesis without an apparent increase in the number of myofibers [19-21].

Insulin Growth Factor-1 (IGF-1) is among the best characterized muscle growth promoting factors. Mainly produced in the liver under the control of the Growth Hormone $(\mathrm{GH})$, its expression is located also in the skeletal muscle, suggesting a paracrine/autocrine role of IGF-1 in positively regulating muscle growth. IGF-1 acts through direct interaction with its own receptor IGF-1 $\mathrm{R}$, a tyrosine-kinase leading to the final activation of AKT by the generation of phosphatidylinositol-3,4,5-triphosphates (PIP3) [20,22-24].

Many studies have established that IGF-1 strongly activates muscle hypertrophy by stimulating the PI3-Kinase/ AKT pathway. IGF can activate any of the three AKT isoforms, and currently both AKT1 and AKT2 have been implicated in myogenesis. Protein levels of AKT1 remains constant from proliferating to differentiating cells, whereas the levels and activity of AKT2 increase with differentiation [25]. AKT, in turn, activates the downstream kinase mTOR, which stimulates p70 S6 kinase and other effectors, ultimately culminating in enhanced protein synthesis [22-24].

\section{Resveratrol properties}

Resveratrol (RSV) (3,5,4' -trihydroxystillbene) belongs to the huge group of polyphenols found naturally in a variety of plants, especially in the peel of grapes and peanuts. RSV has received important attention because of a number of reports highlighting its benefits in vitro and in vivo in a variety of human disease, including cardioand neuroprotection, immune regulation, cancer chemoprevention, DNA repair, Sirtuins activation, prevention of mitochondrial disorder, avoidance of obesity-related diseases [26-40].

The versatility of RSV lies in its diverse targeting of membrane and intracellular receptors, signaling molecules, biogenesis enzymes, oxidative systems, DNArepair mechanisms and transcription factors, as well as in the wide range of possible RSV-induced effect, including cellular proliferation, cell-cycle arrest, differentiation and cell death $[26,27,29]$.

To elucidate the underlying mechanism of RSV action, much research has been focused on different tissues and cell types such as myocardial cells and hepatocytes [30-32,37]. But, since RSV has been shown to act on skeletal muscle metabolism and function [41-45], less attention has been given to its effects on myogenesis [46].

\section{In vitro model for myogenesis study}

C2C12 murine immortalized cell line provides a good in vitro model for the study of the major steps of myoblasts proliferation and differentiation [6,47-50].

In this cellular model, undifferentiated myoblasts are recognizable as flat, fusiform or star-shaped cells, which appeared scattered on the substrate and rigorously mononucleated. After reaching confluence or 24 hour after serum removal, $\mathrm{C} 2 \mathrm{C} 12$ cells are considered myoblasts in an early differentiation stage and they are characterized by changes in myoblasts orientation, lengthening and thickening. Later, confluent mononucleated myocytes begin to fuse forming multinucleated myotubes (intermediate differentiation), positive for the characteristic muscle-specific protein MyHC. Myotubes become wider and longer over the next few days as additional myocytes fusion. Multinucleated and large myotubes appear to form a network with numerous nuclei arranged in multiple linear arrays (late differentiation) (Figure 1A).

In the present work we investigated potential mechanisms mediating the effects of two different doses of Resveratrol $(0.1 \mu \mathrm{M}$ and $25 \mu \mathrm{M})$ on cell cycle regulation, skeletal muscle differentiation and during the genesis of hypertrophy in $\mathrm{C} 2 \mathrm{C} 12$ myoblastic cells (Figure 1B).

\section{Methods}

Materials

Mouse C2C12 myoblastic cells were purchased from the European Collection of Animal Cell Cultures (ECACC). Reagents were purchased from Sigma Chem. (St. Louis, MO, U.S.A.). Primary antibodies: anti-MyoD (C-20), anti-Myf-5 (C-20), anti-Akt1/2 (N-9), anti-MyHC (H-300), anti-p21 (C-19), anti-Myogenin (D-10), anti-Calnexin (H-70), antiGDF-8 (N-19), anti-IGF-1 (G-17), anti-N-Cadherin (H-63), anti-p120 (H-90), anti-AMPK $\alpha 1 / 2$ (H-300), anti-pERK1/2 (E-4), anti-ERK1 (K-23), anti-ERK2 (C-14), anti-p53 (FL393) monoclonal or polyclonal primary antibodies and the peroxidase-conjugated or rhodamine-conjugated secondary antibodies were purchased from Santa Cruz Biotechnology (Santa Cruz, CA, U.S.A.). Alpha-Sarcomeric Actinin primary antibody was purchased from Sigma Chem. Co. (St. Louis, MO, USA). Anti-phospho-Akt (Ser 473)(D9E) and phospho-AMPK $\alpha$ (Thr 172) (40H9) were purchased from Cell Signaling Technology (Danvers, MA, U.S.A.).

In particular, Resveratrol was purchased from Sigma Chem. (St. Louis, MO, U.S.A.) and, according to the manufacturer's instruction, it was dissolved in sterile water.

\section{Experimental procedures}

$\mathrm{C} 2 \mathrm{C} 12$ cells were maintained at $37^{\circ} \mathrm{C}$ in humidified $5 \%$ $\mathrm{CO} 2$ atmosphere in a growth medium containing DMEM (Dulbecco Modified Eagle Medium) supplemented with 
$20 \%$ (v/v) FBS (Fetal Bovine Serum), 1\% penicillinstreptomycin and 1\% L-glutamine up to $70 \%$ confluence.

During proliferation phase, cells, seeded at $6 \times 10^{2}$ cells $/ \mathrm{cm}^{2}$, were maintained in mitogen-rich growth medium (GM) as single myoblasts. These proliferating cells were treated with RSV 0.1 and $25 \mu \mathrm{M}$. These two doses represent the optimal concentrations to induce effects on differentiation process without any significant toxicity for cells $[42,46]$. This observation was validated by our growth curve and cell viability test.

According to RSV half-life, medium was changed every 8 hours.

Mouse myoblast $\mathrm{C} 2 \mathrm{C} 12$ immortalized cell line is a subclone of $\mathrm{C} 2$ myoblasts, which spontaneously fuse and differentiate into multinucleated myotubes as a result of both the achievement of myoblast confluence (as in the case of cells seeded in growth medium with 20\% FBS = GM) and the removal of the serum growth factors (as for cells transferred in DMEM supplemented with 1\% HS, Horse Serum = DM) [6,47-50]. Figure 1B explains experimental study design in each phase of the protocol, with cell confluence percentage, treatments start time and duration.

RSV action was evaluated by Real-Time-PCR, Western Blot and Immunofluorescence analysis during proliferation phase and in the induction, progression and termination of myogenesis. RSV effects on hypertrophy process were also studied.

\section{Growth curve and cell viability test}

To study RSV action on C2C12 myoblast proliferation, we performed growth curve assay as described [51].

C2C12 myoblasts were plated in $60 \mathrm{~mm} \times 15 \mathrm{~mm}$ culture dishes at $40 \%$ confluence and grown in GM with or without RSV (0.1 and $25 \mu \mathrm{M})$. Medium was changed every $24 \mathrm{~h}$ and the experiment lasted until control cells achieved $70 \%$ of confluence (3 days) (Figure 1B).

Every day, the cells were trypsinized and stained with trypan blue. Both viable (non-stained) and non-viable (blue) cells were counted using a hemacytometer. The total cell count average values for each single day were used to plot a growth curve for myoblasts treated with RSV $(0.1$ and $25 \mu \mathrm{M})$ and control (GM and DM). Cell viability was calculated by dividing the non-stained viable cell count by the total cell count.

In addition, every day morphological changes were examined.

\section{Real-Time-PCR (RT-PCR) array analysis}

$\mathrm{RT}^{2}$-PCR Array plates produced by SABiosciences (SABiosciences Corporation, Frederick, MD 21703 USA) were utilized to simultaneously analyze the expression levels of a panel of genes.
We studied the following genes expression during proliferation phase (24 h): Cyclin A2, Cyclin B1, Cyclin C, Cyclin D1, Cyclin E1 and Cyclin F, using Mouse Cell Cycle $\mathrm{RT}^{2}$ Profiler $^{\mathrm{Tm}}$ PCR Array, as described [52].

Total RNA was isolated from $\mathrm{C} 2 \mathrm{C} 12$ using the RNeasy Plus Mini Qiagen Kit (Qiagen GmbH, Germany). Total RNA $(1 \mu \mathrm{g})$ was reverse transcribed using $\mathrm{RT}^{2}$ First Strand Kit (SABiosciences Corporation, Frederick, MD 21703 USA). The reverse transcripts were used as templates for analysis of gene expression level using $\mathrm{RT}^{2}$ - PCR Arrays plates according to the manufacturer's instructions. Each sample was run in triplicate. The expression level of the housekeeping genes chosen for normalization in the threshold cycle $(\mathrm{Ct})$ for each experimental conditions and then the fold-change $(\Delta \Delta \mathrm{Ct})$ for each gene from treated group compared to the control group (GM control time 0), was calculated. If the $\Delta \Delta \mathrm{Ct}$ is greater than 1 , the result may be reported as a fold up-regulation. If the $\Delta \Delta \mathrm{Ct}$ is less than 1 , the result may be reported as a fold down-regulation.

\section{Electrophoretic techniques and immunoblotting analysis}

C2C12 myofibers were homogenized in lysis buffer (50 mM Tris/ $\mathrm{HCl}, \mathrm{pH} 7.4,150 \mathrm{mM} \mathrm{NaCl}, 1 \%$ Triton X100, $1 \mathrm{mM}$ sodium orthovanadate $\left(\mathrm{Na}_{3} \mathrm{VO}_{4}\right), 1 \mathrm{mM}$ EDTA, $1 \mathrm{mM}$ PMSF, $1 \mathrm{mg} / \mathrm{ml}$ aprotinin, $1 \mathrm{mg} / \mathrm{ml} \mathrm{leu-}$ peptin, $1 \mathrm{mg} / \mathrm{ml}$ pepstatin) and shaked for $1 \mathrm{~h}$ at $4^{\circ} \mathrm{C}$. Detergent-insoluble material was removed from the cell suspension by centrifugation at $12,000 \times \mathrm{g}$ for $30 \mathrm{~min}$. Proteins content was quantified using Bradford method. Aliquots of $30 \mu \mathrm{g}$ supernatant proteins from the different samples were resolved by SDS-PAGE. Electrophoresed proteins were transferred to nitrocellulose membrane (Protran ${ }^{\oplus}$, Whatman ${ }^{\oplus}$ Schleicher \& Schuell) as described [53]. The membranes were incubated with specific antibodies and then incubated with HRPconiugated anti species-specific secondary antibodies. Immunoreactive bands were visualized by an enhanced chemiluminescence method (Amersham Pharmacia Biotech, Piscataway, NJ, USA) The membrane was stripped and reprobed with an antibody $\alpha$-calnexin to confirm equal protein loading per sample.

Quantitative measurement of immunoreactive bands was performed by densitometric analysis using the Scion image software (Scion Corporation, Frederick, MD, USA).

Data were then presented as fold change (FC) of the control.

\section{Immunofluorescence analysis}

For indirect immunofluorescence, $\mathrm{C} 2 \mathrm{C} 12$ cells were fixed in $4 \%$ paraformaldehyde, permeabilized with $0.2 \%$ Triton X-100, and blocked with PBS containing 1\% bovine serum albumin. Cells were then immunostained with specific antibodies rhodamine-conjugated (Santa 
Cruz Biotechnology, California, USA) and nuclei revealed with DAPI staining. Cells were observed using fluorescence Leica DM IRE2 microscopy and Nikon Eclipse 50I microscopy and images of myotubes were captured using respectively IM50 software and Nis-Elements D 4.00 software (Leica Microsystems, Switzerland and Nikon Instruments Europe BV, Netherlands) for size comparison. Data were displayed and analyzed using Adobe ${ }^{\odot}$ Photoshop ${ }^{\circledR}$ CS4.

For myotubes length and diameter size, the average measurement on each slide was generated from approximately 150 myotubes. 10 fields were randomly chosen and all MyHC-positive multinucleated cells containing at least 3 nuclei in each field were measured. The data were then converted to percentage increase of the control (DM). To quantify the differentiation and fusion of C2C12 cells after treatments, we calculated the fusion index as the average number of nuclei in of $\mathrm{MyHC}$ positive multinucleated cells above total nuclei. In the same way, the data were then converted to percentage increase of the control (DM).

\section{Statistical analysis}

All experiments were performed three times. For array, immunoblotting and Immunofluorescence analysis, statistical evaluations were performed by t-test. Data are presented as the mean \pm SD. Results were considered statistically significant if $\mathrm{p} \leq 0.05$.

\section{Results}

\section{Proliferative phase}

In proliferative phase, we investigated MRFs protein synthesis and morphologic features in $\mathrm{C} 2 \mathrm{C} 12$ cells after exposure to 0.1 or $25 \mu \mathrm{M}$ of RSV for different time periods (Figure 1B). We used a control in which RSV was not added to the medium (GM or DM).

We first examined RSV action on $\mathrm{C} 2 \mathrm{C} 12$ proliferation rate. Every day, growth time and morphologic feature changes of $\mathrm{C} 2 \mathrm{C} 12$ were evaluated.

Proliferation curve, in Figure 2A, showed that RSV treatment induced a decrease of cell division with respect to untreated control cells (GM). This effect was dose-dependent: RSV $0.1 \mu \mathrm{M}$ had a minimal effect, comparable to untreated cells, while the highest concentration, RSV $25 \mu \mathrm{M}$, showed an important action on proliferation control. (Day 1: DM vs GM p $\leq 0.05$; Day 2: $D M$ vs $G M p \leq 0.05$. Day 3: DM vs $G M p \leq 0.05$, RSV $25 \mu \mathrm{M}$ vs $\mathrm{GM} \mathrm{p} \leq 0.05)$.

In Figure $2 \mathrm{~B}$, viability assay graph showed the absence of cell mortality in all treatment conditions.

A very important support to those data were the morphological changes observed in cells treated with $25 \mu \mathrm{M}$ of RSV: the cells seem to lose their characteristic circular shape, typical of the active proliferation phase, to achieve a new elongated morphology. Phase contrast images, collected at day 3 of growth curve, confirmed those morphological features (Figure 2C): morphological changes in cell size and shape are compared in detail, emphasizing the analogy between DM cells (differentiation control) and $25 \mu \mathrm{M}$ RSV-treated cells.

Most Cyclins expression seems to decrease with the onset of differentiation, when cells are blocked in G1 phase [1]. To achieve additional confirmation of data obtained from the growth curve, viability test and morphological studies, we performed quantitative Real-TimePCR during proliferation phase (24 h), to prove an actual decrease in Cyclins expression levels (Figure 3A). As shown in the panel, RSV treatments cause a significantly down-regulation in Cyclins expression, following DM control condition, in respect to GM time 0 control (Cyclin A2: DM vs GM T0 p $\leq 0.01$; RSV $25 \mu \mathrm{M}$ vs GM T0 $\mathrm{p} \leq 0.01$. Cyclin B1: DM, RSV 0.1, RSV $25 \mu \mathrm{M}$ vs GM T0 $\mathrm{p} \leq 0.01$. Cyclin D1: DM vs GM T0 p $\leq 0.01$; RSV $25 \mu \mathrm{M}$ vs GM T0 $\mathrm{p} \leq 0.01$. Cyclin E1: RSV $0.1 \mu \mathrm{M}$ vs GM T0 $\mathrm{p} \leq 0.01$; RSV $25 \mu \mathrm{M}$ vs GM T0 $\mathrm{p} \leq 0.01$. Cyclin F: DM, RSV 0.1, RSV $25 \mu \mathrm{M}$ vs GM T0 p $\leq 0.01$ ).

To verify the absence of RSV cytotoxic effects on $\mathrm{C} 2 \mathrm{C} 12$, we evaluated in Western Blot analysis the protein levels of the apoptotic marker p53 [54] during proliferation phase (Figure 3B), showing how RSV treatment does not modify p53 protein amount in respect to GM control condition. Phase contrast images in Figure $3 \mathrm{C}$, collected at $24 \mathrm{~h}$ and $72 \mathrm{~h}$ of proliferative phase, illustrated the morphological changes in RSVtreated cells with respect to control.

Furthermore, to corroborate RSV action on cell cycle regulation, we measured the protein content of cell cycle regulator p21 during proliferative phase. RSV treatment (both 0.1 and $25 \mu \mathrm{M}$ ) seems to cause a significant decrease in p21 protein levels with respect to control (DM vs GM p $\leq 0.01$; RSV 0.1 vs GM $\mu \mathrm{M}$ p $\leq 0.01$; RSV $25 \mu \mathrm{M}$ vs GM p $\leq 0.01$ ) (Figure 3B). The lower protein content in RSV-treated cells with respect to growth control (GM) is comparable to differentiation control cells (DM). Since p21 promotes cell cycle exit and induces cellular differentiation $[5,55,56]$, we might suppose that RSV could induce cell cycle arrest and differentiation.

To investigate RSV action on differentiation induction, we determinated protein amount of two early MRFs: MyoD and Myf-5, key markers of differentiation induction [1-8].

Figure 4A elucidated the significant increase of Myf-5 and MyoD protein levels after RSV stimulation (Myf-5: DM vs $G M p \leq 0.01$; RSV $25 \mu \mathrm{M}$ vs GM p $\leq 0.01$; RSV 0.1 vs GM p $\leq 0.05$ ) (MyoD: DM vs GM p $\leq 0.01$; RSV $25 \mu \mathrm{M}$ vs GM p $\leq 0.05)$.

In addition, we studied morphological changes in myoblasts through MyoD and Myf-5 Immunofluorescence 


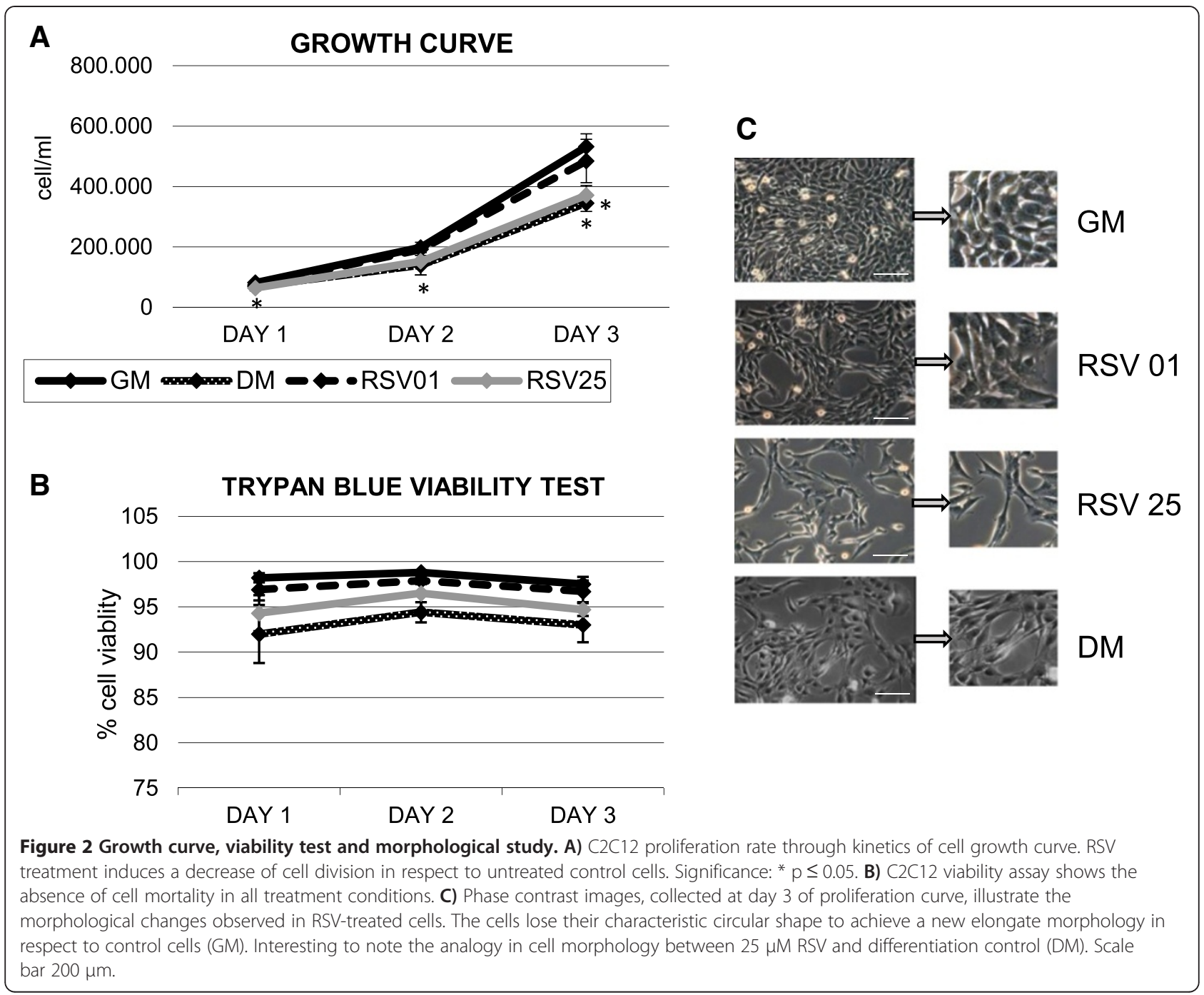

analysis during proliferative phase ( $24 \mathrm{~h}$, Figure $4 \mathrm{~B}-\mathrm{C})$. Knowing that MyoD and Myf-5 represent important markers for early myogenesis stage and regulates skeletal muscle commitment [6,7], these results prove that RSV can advance differentiation induction.

The absence of resveratrol cytotoxicity, associated with a decrease in mRNA expression of most important Cyclins, a decrement of proliferation rate and morphological changes coupled with a significant rise in early MRFs protein expression led us to suppose that this polyphenol could promote differentiation induction through cell cycle control.

RSV seems to be able to direct the acquisition of a specific myogenic phenotype: from undifferentiated myoblasts to myocites $[2,8]$.

\section{Differentiation induction and progression}

Sequential expression of MRFs at a specific stage is pivotally important for the success of the myogenesis $[1-3,6,8,11,12]$.
To study differentiation induction and progression, we analyzed protein levels of main MRFs and skeletal proteins during early $(24 \mathrm{~h})$, intermediate $(48-72 \mathrm{~h})$ and late (96 h) differentiation by Western Blot.

Figure 5A shows Myf-5 protein levels during differentiation phases: in RSV-treated cells protein content of this early MRFs decreased during differentiation progression until it appeared undetectable $(72 \mathrm{~h})$. Instead, in DM condition Myf-5 protein levels diminished but more slowly than in RSV-treated cells and at 72 hours are still detectable (RSV $0.1 \mu \mathrm{M}$ vs DM 24 h p $\leq 0.05$; RSV 0.1 vs DM $48 \mathrm{~h}$ p $\leq 0.05$; RSV $25 \mu \mathrm{M}$ vs DM $48 \mathrm{~h}$ $\mathrm{p} \leq 0.05)$. RSV treatment might anticipate the protein expression of early MRFs.

Myogenin protein levels, in Figure 5A, confirmed how both 0.1 and $25 \mu \mathrm{M}$ RSV treatments could advance the expression of early MRFs in respect to DM control, promoting differentiation progression (RSV $25 \mu \mathrm{M}$ vs DM 48 h p $\leq 0.05$ ). 


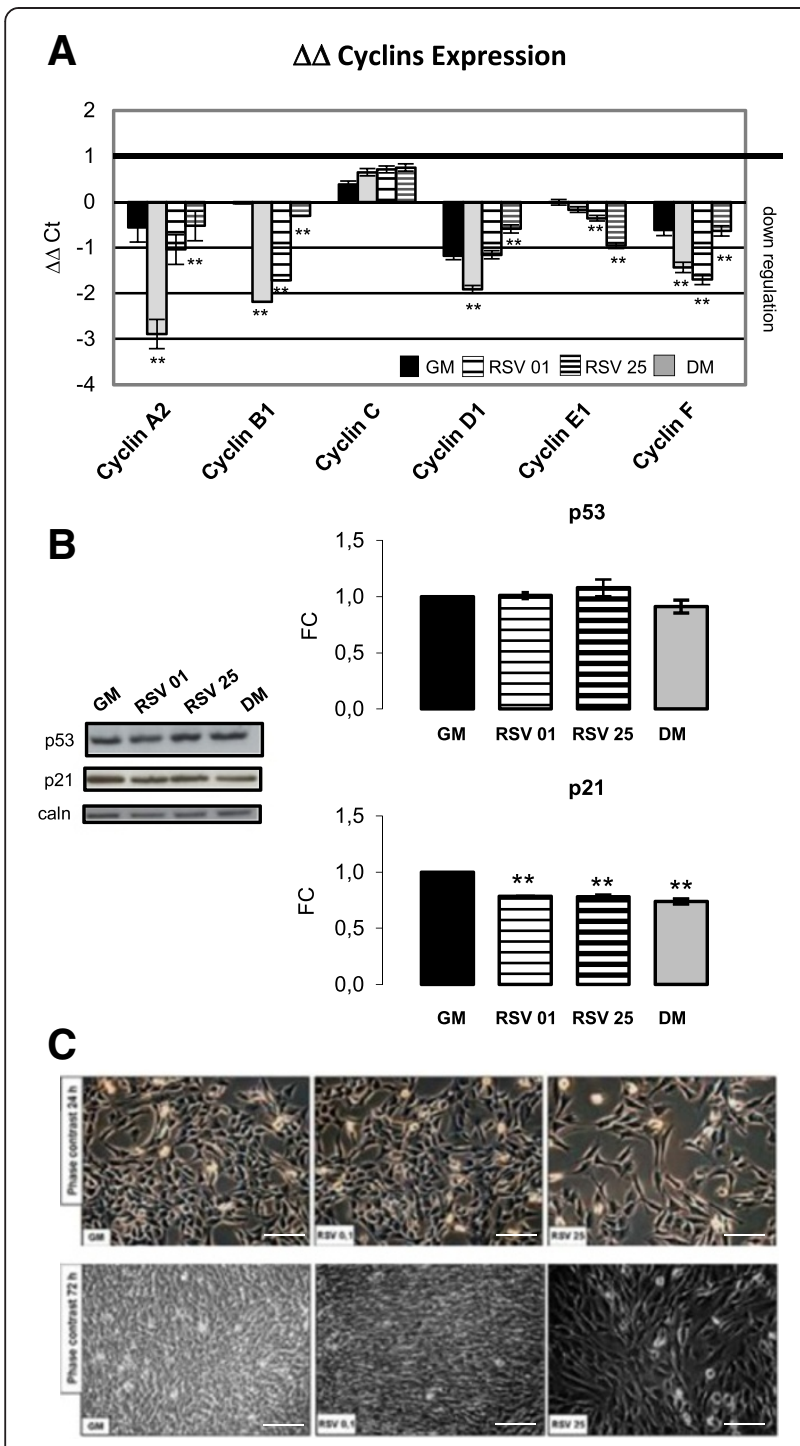

Figure 3 RSV action on cell cycle regulation in proliferation phase. A) Real-Time-PCR during proliferation phase (24 h), proves an actual decrease in Cyclins expression levels after treatment with RSV, in a similar way to DM condition, in respect to GM time 0 condition. Significance: ${ }^{*} p \leq 0.05 ;{ }^{* *} p \leq 0.01$. B) p53 Western Blot analysis, during proliferation phase, shows how RSV treatment does not modify p53 protein amount in respect to GM control condition. p21 Western Blot analysis reveals a significant decrease in protein content in both 0.1 and $25 \mu \mathrm{M}$ RSV-treated cells, following DM trend, in respect to growth control GM. Significance: * $p \leq 0.05 ;{ }^{* *} p \leq 0.01$. Representative immunoblots of analyzed proteins are shown. C) Phase contrast images collected at 24 and $72 \mathrm{~h}$ of proliferative phase show morphological changes mentioned in Figure 2. Scale bar $200 \mu \mathrm{m}$.

For myotubes to form, fusion-competent myoblasts need to migrate towards each other or towards existing myotubes, align and establish close cell-cell contacts so that membranes can fuse [57-59]. N-Cadherin is of utmost importance in this process $[14,60]$. RSV revealed an imperative action on protein levels of key structural proteins N-Cadherin, p120 Catenin, associated with MCadherin activity, and Alpha-Sarcomeric Actinin proteins. Blot in Figure 5A elucidates this effect: during all differentiation stages, RSV treatment significantly increased protein content of specific skeletal proteins responsible of neo-myotubes formation (N-Cadherin: RSV $0.1 \mu \mathrm{M}$ vs DM 24 and $48 \mathrm{~h} \mathrm{p} \leq 0.05$; RSV $25 \mu \mathrm{M}$ vs $\mathrm{DM}$ 24 and $48 \mathrm{~h}$ p $\leq 0.05$ ); (p120: RSV $0.1 \mu \mathrm{M}$ vs DM 72 and $96 \mathrm{~h} \mathrm{p} \leq 0.05$; RSV $25 \mu \mathrm{M}$ vs DM 72 and $96 \mathrm{~h} \mathrm{p} \leq 0.05$ ); (Alpha-Sarcomeric Actinin: RSV $0.1 \mu \mathrm{M}$ vs DM $24,72,96 \mathrm{~h} p \leq 0.05$; RSV $25 \mu \mathrm{M}$ vs DM 24,48,72,96 h $\mathrm{p} \leq 0.05)$.

Graph in Figure 5A illustrates $0.1 \mu \mathrm{M}$ and $25 \mu \mathrm{M}$ RSV effects on MyHC protein expression during all differentiation phases. In particular, $25 \mu \mathrm{M}$ RSV caused an important increase in $\mathrm{MyHC}$ protein content in respect to DM (RSV $25 \mu \mathrm{M}$ vs DM 48 and $72 \mathrm{~h} \mathrm{p} \leq 0.05$ ).

Immunofluorescence analysis after 48 hours of differentiation (Figure 5B-C) provided an additional prove of $\mathrm{RSV}$ role in differentiation progress: images of $\mathrm{MyHC}$ (Figure 5B) and Alpha-Sarcomeric Actinin (Figure 5C) protein expression showed a difference in the number of cells positive for these two structural proteins. Moreover, Figure 5B-C illustrates the highest density of $\mathrm{MyHC}$ and Alpha-Sarcomeric Actinin positive cells in $25 \mu \mathrm{M}$ RSVtreated cells in respect to DM. In RSV conditions cells became more elongated and assumed a bipolar morphology, showing the presence of early myoblasts clusters, in respect to control.

IGF-1 represents the major anabolic factor in skeletal muscle, promoting mitogenic and anabolic effects through the activation of the AKT signaling pathway. Its biological activity requires its binding to a specific receptor (IGF-1 R) [61,62]. IGF-1 R is synthesized as a single polypeptide chain (Pro IGF-1 R) that is processed to mature receptor. As shown in Figure 6A, RSV caused a tendency to increase levels of Pro-IGF-1 R protein and IGF$1 \mathrm{R}$ protein during all analyzed differentiation time (ProIGF-1 R: RSV $0.1 \mu \mathrm{M}$ vs DM $24 \mathrm{~h} \mathrm{p} \leq 0.01 ; 48 \mathrm{~h} \mathrm{p} \leq 0.05$; RSV $25 \mu \mathrm{M}$ vs DM $24 \mathrm{~h} \mathrm{p} \leq 0.05)$ (IGF-1 R: RSV $0.1 \mu \mathrm{M}$ vs DM $24 \mathrm{~h} \mathrm{p} \leq 0.05)$.

As expected, RSV stimuli increases the phosphorylation state representing activated AKT (Figure 6B): in particular, RSV $0.1 \mu \mathrm{M}$ at $96 \mathrm{~h}$ of differentiation and RSV $25 \mu \mathrm{M}$ at 72 and $96 \mathrm{~h}$ after differentiation induction (pAKT/AKT: RSV $0.1 \mu \mathrm{M}$ vs DM $96 \mathrm{~h} \mathrm{p} \leq 0.05$; RSV $\mu \mathrm{M}$ vs DM 72, $96 \mathrm{~h} \mathrm{p} \leq 0.05)$.

Widely described in literature is the important role of ERK 1/2 MAP kinases signaling in muscle differentiation and cell fusion to induce hypertrophy $[63,64]$. Protein quantification in Figure 6C shows RSV action on ERK 1/ 2 activation during differentiation (pERK1/ERK: RSV $0.1 \mu \mathrm{M}$ vs DM $24 \mathrm{~h}, 48 \mathrm{~h}, 72 \mathrm{~h}, 96 \mathrm{~h} \mathrm{p} \leq 0.05$; RSV $25 \mu \mathrm{M}$ vs DM $24 \mathrm{~h}, 48 \mathrm{~h}, 72 \mathrm{~h} \mathrm{p} \leq 0.05$ ) (pERK2/ERK2: 


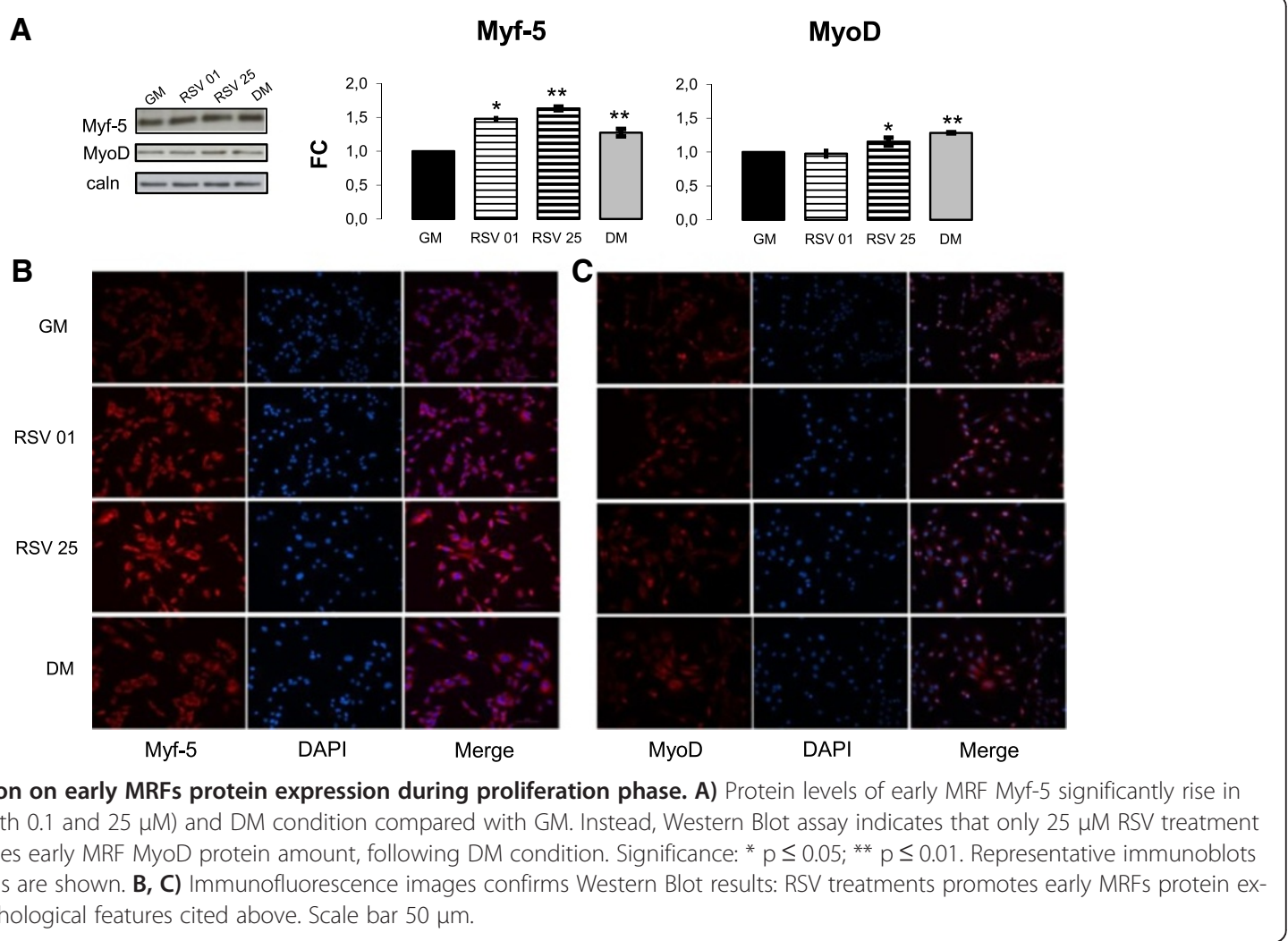

RSV $0.1 \mu M$ vs DM 48 h, 72 h, 96 h p $\leq 0.05$; RSV $25 \mu \mathrm{M}$ vs DM 48 h, 72 h, 96 h p $\leq 0.05)$.

AMPK seems to be an essential regulator of muscle cell size maintenance through the control of mTORC1 pathway and can play a major role in the metabolic program that organize muscle plasticity [16-18]. RSV is able to significantly regulate the levels of this important protein. As shown in blot in Figure 6D, RSV caused a significant raise in AMPK protein content during all phases of differentiation (AMPK: RSV $0.1 \mu \mathrm{M}$ vs DM $24 \mathrm{~h}$, $48 \mathrm{~h}, 72 \mathrm{~h} \mathrm{p} \leq 0.05 ; 96 \mathrm{~h} \mathrm{p} \leq 0.01$; RSV $25 \mu \mathrm{M}$ vs DM $24 \mathrm{~h}, 48 \mathrm{~h}, 72 \mathrm{~h} \mathrm{p} \leq 0.05)$. Furthermore, it is important to note how RSV treatment is able to activate AMPK protein also during the last phases of differentiation (pAMPK: RSV $0.1 \mu \mathrm{M}$ vs DM $96 \mathrm{~h} \mathrm{p} \leq 0.05$; RSV $25 \mu \mathrm{M}$ vs DM $72 \mathrm{~h}, 96 \mathrm{~h} \mathrm{p} \leq 0.05)$.

Given the essential role in cellular metabolism of AMPK protein, this RSV effect, obtained after stimulation by these doses, assumes a critical relevance.

\section{Study of the hypertrophic process}

To confirm RSV involvement in the process of hypertrophy, after 72 hours of differentiation, we performed Western Blot analysis to evaluate protein content after $30 \mathrm{~min}$ and 4,8,24 hours of treatment (Figure 1B). Results confirmed the important $\mathrm{MyHC}$ protein content increase in RSV stimulated cells (RSV $0.1 \mu \mathrm{M}$ vs DM $30 \mathrm{~min}, 4 \mathrm{~h}$,
$24 \mathrm{~h}$ p $\leq 0.05$; RSV $0.1 \mu \mathrm{M}$ vs DM $8 \mathrm{~h} \mathrm{p} \leq 0.01$; RSV $25 \mu \mathrm{M}$ vs DM $30 \mathrm{~min}, 4 \mathrm{~h}, 8 \mathrm{~h}, 24 \mathrm{~h} \mathrm{p} \leq 0.05$ ) (Figure 7B).

Furthermore, during post-differentiation phase, the levels of key structural proteins like N-Cadherin remained high compared to DM control (Figure 7B) (RSV $0.1 \mu \mathrm{M}$ vs DM $30 \min , 4 \mathrm{~h} \mathrm{p} \leq 0.01 ; 8 \mathrm{~h}, 24 \mathrm{~h} \mathrm{p} \leq$ 0.05 ; RSV $25 \mu \mathrm{M}$ vs DM 30 min $\mathrm{p} \leq 0.01 ; 4 \mathrm{~h}, 8 \mathrm{~h}, 24 \mathrm{~h}$ $\mathrm{p} \leq 0.05)$.

The same happened for AMPK protein content (RSV $0.1 \mu \mathrm{M}$ vs DM $8 \mathrm{~h} \mathrm{p} \leq 0.01$; RSV $25 \mu \mathrm{M}$ vs DM $30 \mathrm{~min}, 4 \mathrm{~h}$ $\mathrm{p} \leq 0.01 ; 24 \mathrm{~h} \mathrm{p} \leq 0.05)$ in Figure 7B. In Figure 7A, phase contrast images after 72 and 96 hours of differentiation described morphological features in neo-formed hypertrophic myotubes.

After 8 hours of RSV treatment, Immunofluorescence was performed to study morphological changes of neoformed myotubes (Figure 7C), monitoring the espression of most important cytoskeletal structural proteins: N-Cadherin and Catenin p120.

Images in Figure 8, collected after 72 hours of differentiation and 8 hours of RSV treatment, showed the significant increase in size of neo-formed myotubes: increase of length and diameter along with the new central disposition of the nuclei was the evidence of hypertrophy genesis [59,65-67].

To support the RSV involvement in muscle hypertrophy, myotubes dimensions were measured in $\mathrm{MyHC}$ images (Figure 8B). 


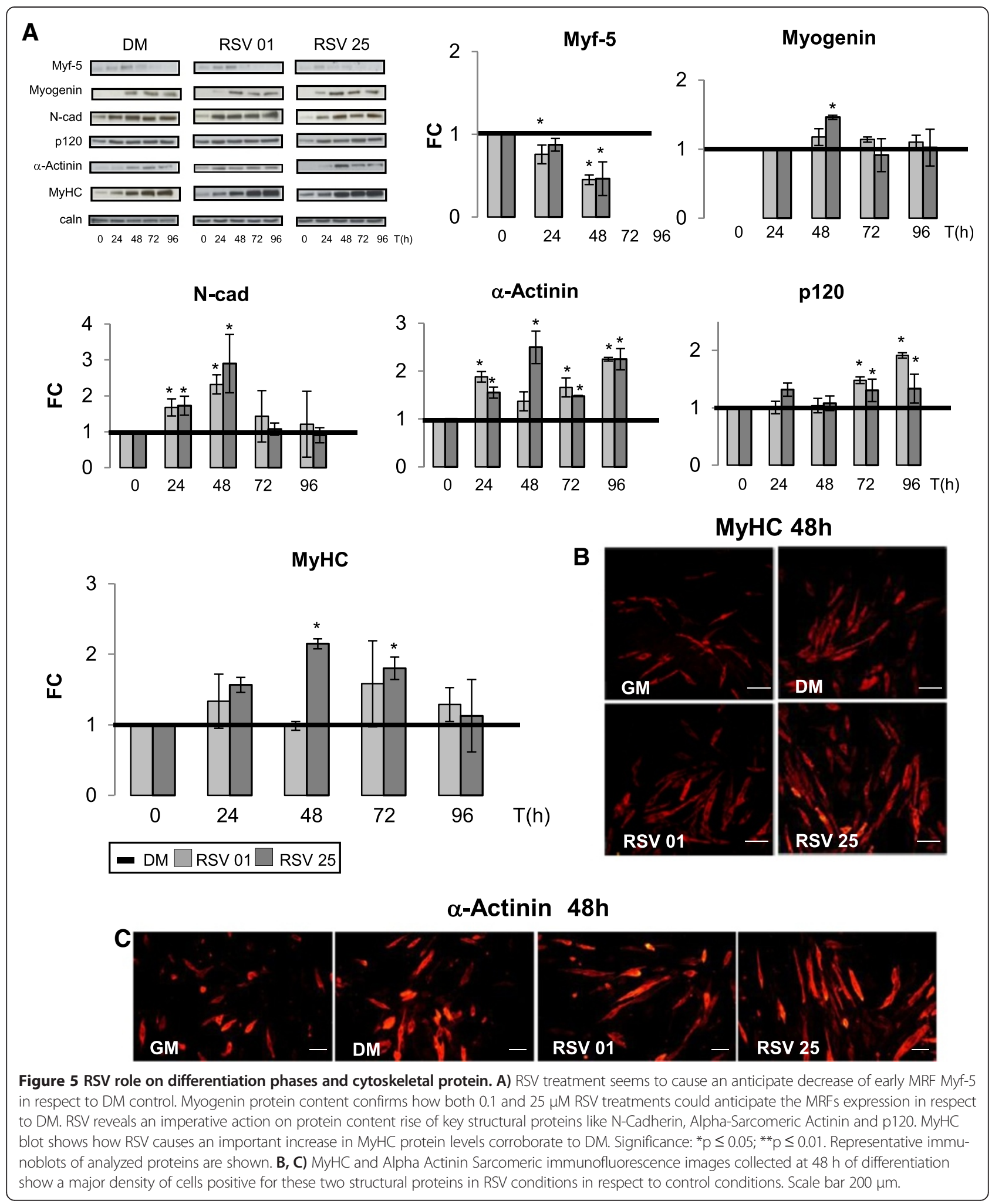

We showed the significant increment in length, diameter and fusion index of RSV-treated myotubes compared to DM condition, in agreement with the evidence that skeletal muscle hypertrophy is characterized by an increase in myofiber size (Figure 8) (Myotubes length: RSV $25 \mu \mathrm{M}$ vs DM $\mathrm{p} \leq 0.01$; Myotubes diameter: RSV $0.1 \mu \mathrm{M}$ vs DM $\mathrm{p} \leq 0.05$; RSV $25 \mu \mathrm{M}$ vs $\mathrm{DM} \mathrm{p} \leq 0.01$; Fusion index: RSV $25 \mu \mathrm{M}$ vs DM p $\leq 0.05)$. 

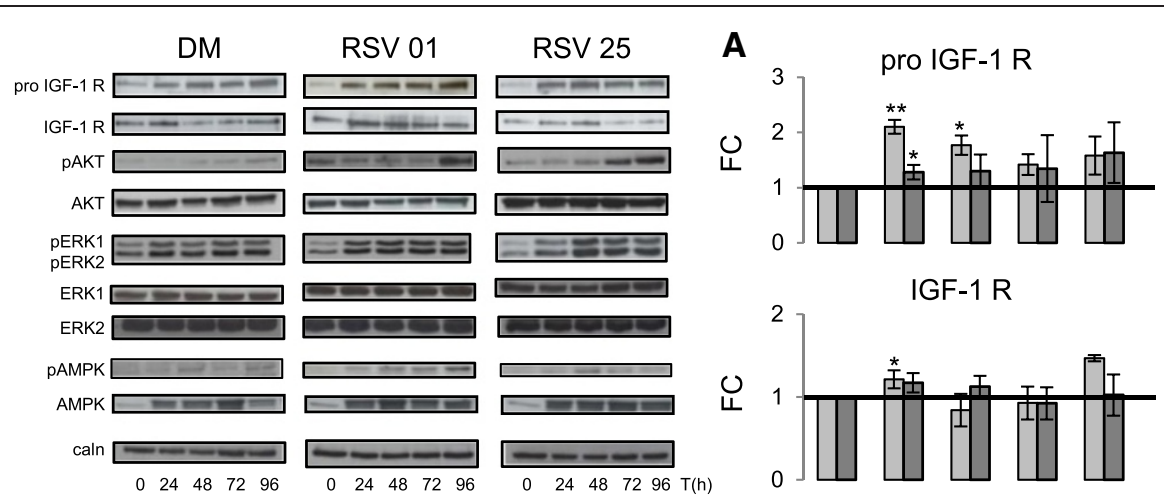

B

PAKT/AKT

D

AMPK
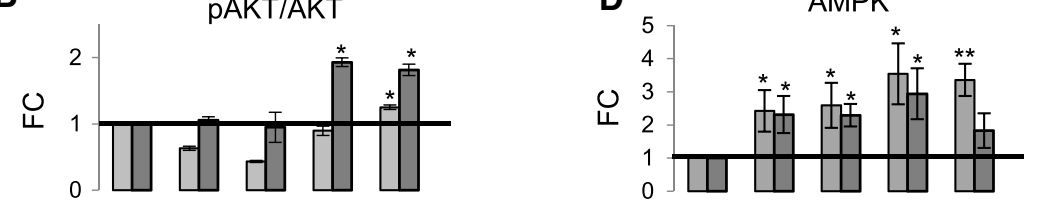

C
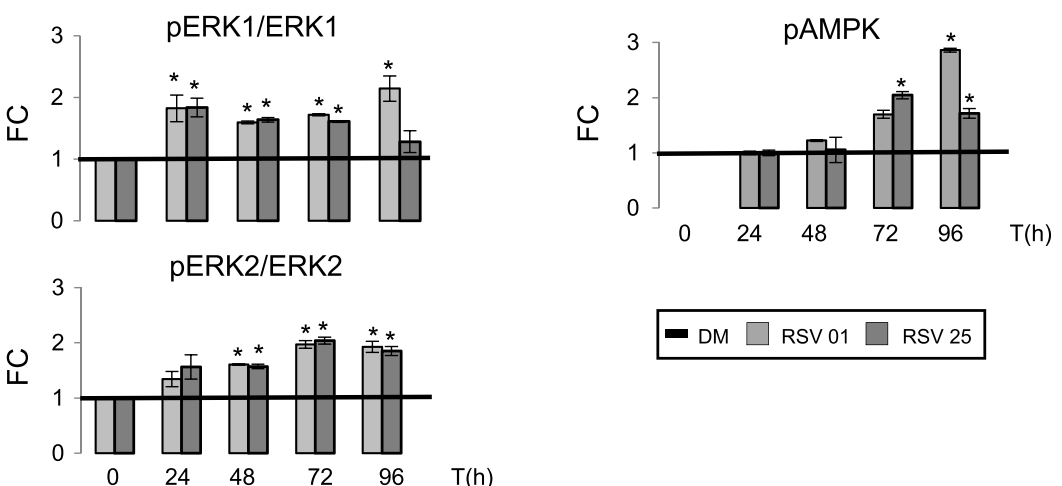

- DM $\square$ RSV $01 \square$ RSV 25

Figure 6 RSV action on IGF and ERKs signaling pathways during differentiation phases. A) Western Blot analysis shows how RSV treatments cause a tendency to increase levels of Pro-IGF-1 R protein and IGF-1 R protein during differentiation. B) In the last phase of differentiation, RSV promotes AKT activation. C) Furthermore, RSV stimuli enhances ERK pathways in all differentiation phases. D) As shown in the panel, RSV seems to cause a significant improve in AMPK protein content during all phase of differentiation and, in the end of differentiation, RSV also promotes AMPK activation. Significance: * $p \leq 0.05 ;{ }^{* *} p \leq 0.01$. Representative immunoblots of analyzed proteins are shown.

To assess changes in myotubes nuclear disposition during late phase of differentiation, we performed Immunofluorescence studies (Figure 8A-C-D) using antibodies against $\mathrm{MyHC}$, Myostatin and p21 proteins, which are involved in terminal muscle differentiation. RSV-treated myotubes are characterized by a particular arrangement of the nuclei to form a ring, representing a morphological marker of in vitro muscle hypertrophy and maturation $[65,67]$.

\section{Discussion}

Previous studies have demonstrated that the natural polyphenolic phytoalexin Resveratrol possesses various biological, biochemical and physiological actions including anti-inflammatory, anti-oxidant, anti-proliferative, promoting differentiation, and chemo preventive effects in pathological conditions like age-related diseases, cardiovascular diseases, cancer, type 2 diabetes and neurological conditions [26-40].

In skeletal muscle, RSV is involved in muscle metabolism regulation, protein catabolism and function, is able to confer resistance against oxidative stress, injury and death of skeletal muscle cells. Besides, RSV has been shown to improve strength and endurance of skeletal muscle [41-46].

Increasing evidence suggests that RSV has an active role in skeletal muscle differentiation [26,41-46]. However, the mechanisms underlying these RSV-induced adaptations have not been completely elucidated.

In our in vitro work, investigating the role of RSV on C2C12 myoblasts growth capacity, we observed its ability to reduce cells proliferation. In support to this result, proliferation rate observed in cell growth curve, elucidates RSV role in the interruption of proliferation. RSV 


\section{A}
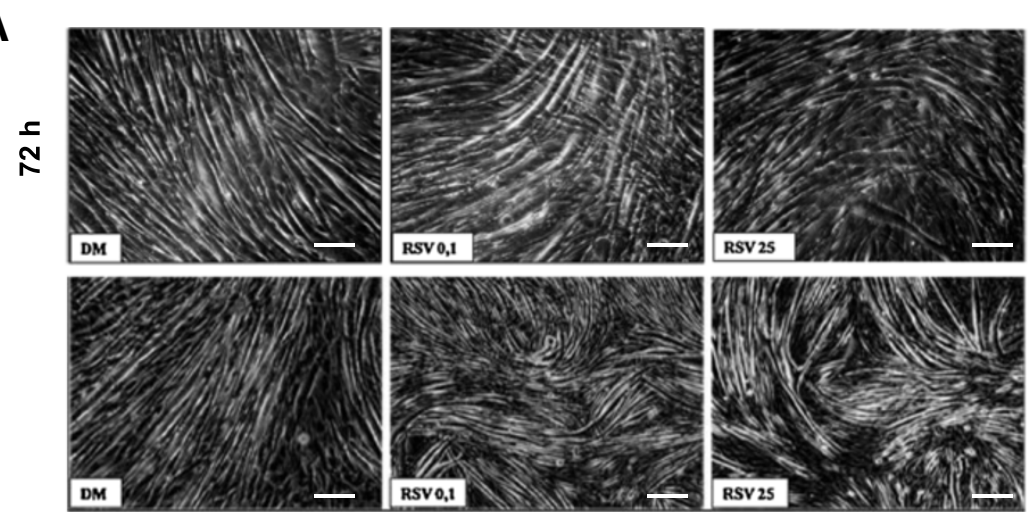

B
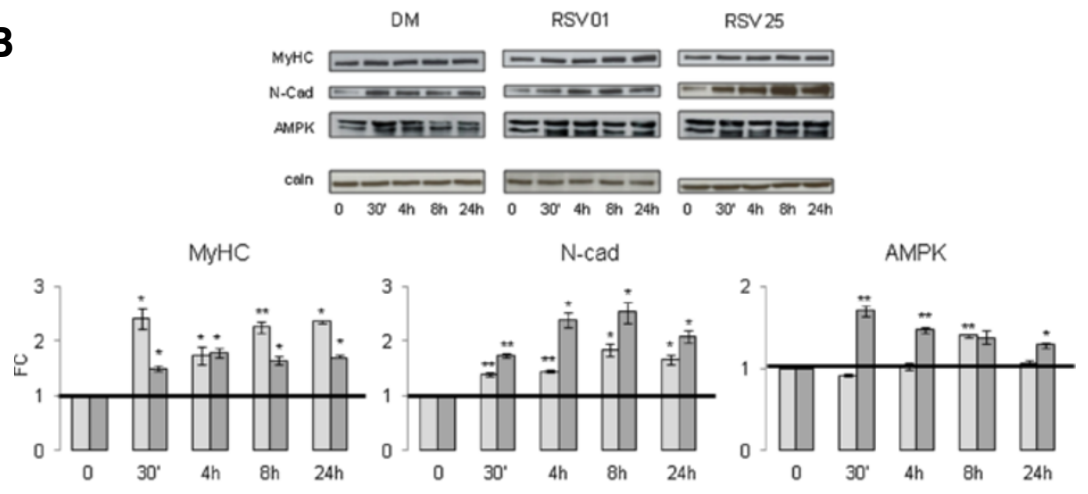

- DM $\square$ RSV $01 \square$ RSV 25

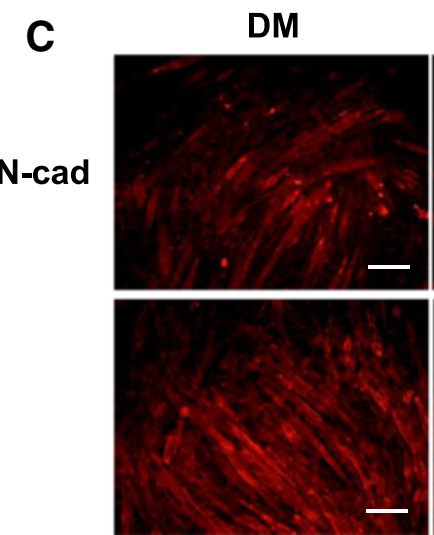

RSV 01

RSV 25

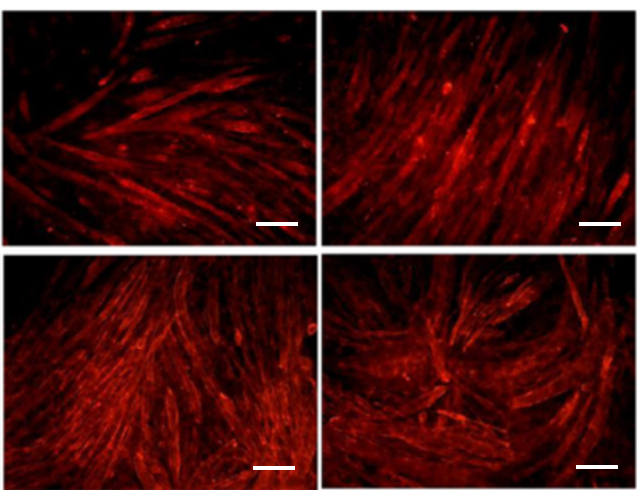

p120

Figure 7 Protein expression during post-differentiation. A) Phase contrast images in post-differentiation phase (72 and 96 hours) showed hypertrophy in neo-formed myotubes treated with RSV, in respect with control. Scale bar $200 \mu \mathrm{m}$. B) Western Blot analysis shows how RSV treatments during post-differentiation phase cause a significant increase in $\mathrm{MyHC}$ protein content. Key structural N-Cadherin protein expression is significantly higher than DM. RSV treatments seem to induct a significant rise in AMPK protein content in respect to DM. Significance: * $\mathrm{p} \leq 0.05$; ** $p \leq 0.01$. Representative immunoblots of analyzed proteins are shown. C) Immunofluorescence during post-differentiation phase (8 h treatment), with antibodies anti N-Cadherin and p120 Catenin, shows the main increase in size of neo-formed myotubes treated with RSV in respect to DM condition. Scale bar $200 \mu \mathrm{m}$.

effect was visible not only in the kinetics of cell growth, but also in the morphological analysis: RSV-treated cells lose their originally circular shape to achieve a new, specific, elongate morphology, typical of muscle cell phenotype. It is important to specify that RSV inhibits proliferation without causing cell injury: count and daily observation of $\mathrm{C} 2 \mathrm{C} 12$ cells showed the absence of cellular mortality. 


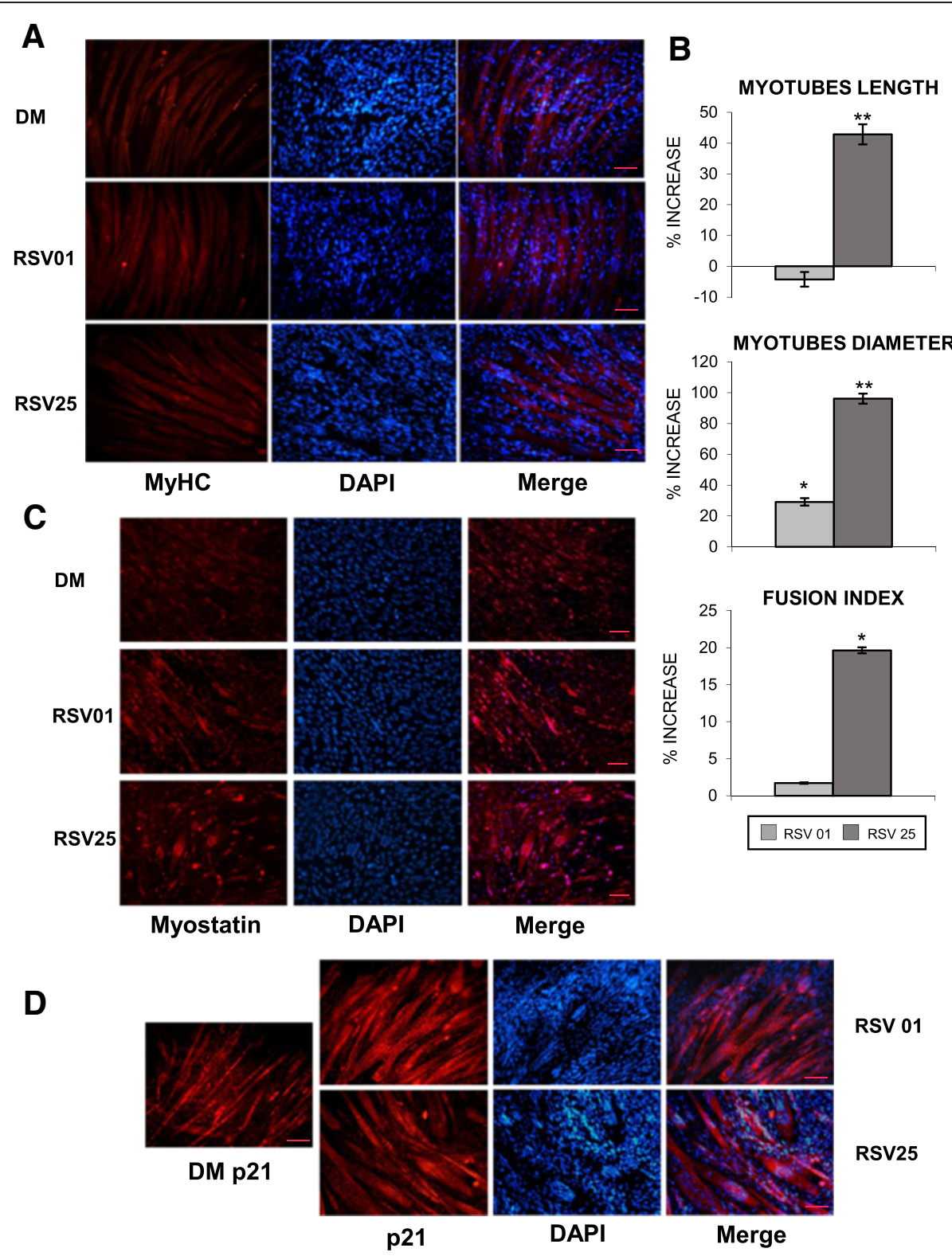

Figure 8 RSV action on MyHC expression, myotubes dimension, nuclei arrangement in hypertrophy (8 $\mathrm{h}$ treatment). A) Immunofluorescence analysis shows hypertrophic morphological changes in MyHC-positive neo-formed myotubes after RSV treatment. Scale bar $50 \mu \mathrm{m}$. B) Graphical representation of the significant increment in length, diameter and fusion index of RSV-treated myotubes compared to DM. Significance: ${ }^{*} p \leq 0.05 ;{ }^{* *} p \leq 0.01$. C) Myostatin Immunofluorescence images show the nuclei arrangement to form a ring in the central section of myotube, marker of in vitro hypertrophy and maturation, particularly evident in the DAPI nuclei coloration. Scale bar 50 m. D) p21 Immunofluorescence images and DAPI also confirm the nuclei arrangement in neo-formed myotubes after RSV treatments in respect to DM condition. Scale bar $50 \mu \mathrm{m}$.

Since activation of muscle differentiation program requires irreversible cell cycle withdrawal of $\mathrm{C} 2 \mathrm{C} 12$ myoblasts and tissue-specific gene expression, our study was extended investigating the effect of 0.1 and $25 \mu \mathrm{M}$ RSV on $\mathrm{C} 2 \mathrm{C} 12$ myoblasts cell cycle exit. p21 expression is a key event in triggering cell cycle withdrawal and myoblasts differentiation $[13,55,56]$.
During proliferative phase, Western Blot analysis revealed how p21 protein content in DM and RSV (both 0.1 and $25 \mu \mathrm{M}$ ) were super imposable, showing that in these two conditions differentiation process progresses faster than in the growth control condition $(\mathrm{GM})$, wherein the differentiation is only determined by cell contact. 
Protein expression of Myf-5 and MyoD transcription factors, myogenic markers already expressed in undifferentiated proliferating myoblasts, was also increased with RSV treatment. In phase contrast and Immunofluorescence images during proliferation phase, the morphological changes mentioned above were clearly visible.

All together, these data support the hypothesis that RSV could regulate myoblasts cell cycle, inducing differentiation process.

The study of differentiation showed how RSV seems to be able to promote the process: 1) inducing the muscle phenotype determination by early expression of MRFs (Myf-5, MyoD and Myogenin), muscle marker proteins $(\mathrm{MyHC})$ and key skeletal structural proteins (N-Cadherin, p120, Alpha Actinin); 2) activating important signaling pathways, including AKT and MAP kinases; 3) causing morphological changes like myoblasts elongation, increase in length and diameter, rise of fusion trend of mono-nucleated myocytes into multinucleated myotubes.

In neo-formed myotubes, RSV seems to maintain hypertrophy process, increasing myotubes size and regulating nuclei arrangement.

Importantly, the present in vitro finding may have a potential impact in in vivo regulation of protein metabolism. In fact, given RSV action on MRFs and musclespecific skeletal proteins synthesis joined to the control of AMPK, IGF-1 R [68], AKT [69] and ERK proteins, we may speculate a hypothetical clinical use of this natural polyphenol in conditions of muscle mass damage/hypotrophy. To achieve this aim it is important to further clarify the connection between used RSV doses and observed effects. In fact, several authors indicated that RSV, used in other different doses, shows controversial anti-inflammation and insulin resistance effects [70].

\section{Conclusions}

In summary, our data demonstrate that Resveratrol could control proliferation, start myogenesis process and induce hypertrophy. RSV seems to be able to regulate cell cycle progression, the following cell cycle arrest and early induction of differentiation, through its action on the expression of specific cell cycle regulators, myogenic regulatory factors and muscle-specific structural proteins.

Our in vitro studies may constitute novel proof of principle to potential applications of the compound to prevent or reverse muscle impairment by stimulating myogenesis, and emphasize new possible use of RSV to enhance muscle performance.

\section{Competing interests}

The authors declare that they have no competing interests.

\section{Authors' contributions}

Conceived and designed the experiments: AM, LL, PS, IT. Performed the experiments: AM, PS, IT. Analyzed the data: AM, LL, PS, NM, IT. Wrote the paper: AM, LL, PS, IT. IT had primary responsibility for the final content. All authors read and approved the final manuscript.

\section{Author details}

${ }^{1}$ Department of Biomedical Sciences for Health, University of Milan, Milan, Italy. ${ }^{2}$ Metabolism Research Centre and Department of Endocrinology and Metabolic Diseases, San Donato Hospital and Scientific Institute, Milan, Italy. ${ }^{3}$ Division of Metabolic and Cardiovascular Sciences, Metabolism,

Nutrigenomics and Cellular Differentiation Unit, DIBIT-San Raffaele Scientific Institute, Milan, Italy.

Received: 29 July 2013 Accepted: 5 December 2013 Published: 13 December 2013

\section{References}

1. Knight DR, Kothary R: The myogenic kinome: protein kinases critical to mammalian skeletal myogenesis. Skelet Muscle 2011, 1:29.

2. Bentzinger CF, Wang YX, Rudnicki MA: Building muscle: molecular regulation of myogenesis. Cold Spring Harb Perspect Biol 2012, 4(2):a008342.

3. Perry RL, Rudnick MA: Molecular mechanisms regulating myogenic determination and differentiation. Front Biosci Sep 2000, 5:D750-67.

4. Kitzmann M, Fernandez A: Crosstalk between cell cycle regulators and the myogenic factor MyoD in skeletal myoblasts. Cell Mol Life Sci 2001, 58:571-579.

5. De Falco M, De Luca A: Involvement of cdks and cyclins in muscle differentiation. Eur J Histochem 2006, 50:19-23.

6. Ferri $P$, Barbieri $E$, Burattini $S$, Guescini $M$, et al: Expression and subcellular localization of myogenic regulatory factors during the differentiation of skeletal muscle in C2C12 myoblasts. J Cell Biochem 2009, 108:1302-1317.

7. Berkes CA, Tapscott SJ: MyoD and the transcriptional control of myogenesis. Semin Cell Dev Biol 2005, 16:585-595.

8. Kablar B, Krastel K, Tajbakhsh S, Rudnicki MA: Myf5 and MyoD activation define independent myogenic compartments during embryonic development. Dev Biol 2003, 258:307-318

9. Lluis F, Perdiguero E, Nebreda AR, Munoz-Canoves P: Regulation of skeletal muscle gene expression by p38 MAP kinases. Trends Cell Biol 2006 16(1):36-44.

10. Kook S-H, Choi K-C, Son Y-O, Lee K-Y, et al: Involvement of p38 MAPKmediated signaling in the calpeptin-mediated suppression of myogenic differentiation and fusion in C2C12 cells. Mol Cell Biochem 2008 310:85-92.

11. Dedieu S, Mazères $G$, Cottin P, Brustis JJ: Involvement of myogenic regulator factors during fusion in the cell line C2C12. Int J Dev Biol 2002 46:235-241

12. Sartorelli V, Caretti G: Mechanisms underlying the transcriptional regulation of skeletal myogenesis. Curr Opin Genet Dev 2005, 15(5):528-535

13. Ostrovsky $\mathrm{O}$, Bengal $\mathrm{E}$ : The mitogen-activated protein kinase cascade promotes myoblast cell survival by stabilizing the cyclin-dependent kinase inhibitor, p21WAF1 protein. J Biol Chem 2003, 278(23):21221-231.

14. Taulet N, Comunale F, Favard C, Charrasse S, et al: N-cadherin/p120 catenin association at cell-cell contacts occurs in cholesterol-rich membrane domains and is required for RhoA activation and myogenesis. $J$ Biol Chem 2009, 284(34):23137-23145.

15. Sjöblom B, Salmazo A, Djinović-Carugo K: Alpha-actinin structure and regulation. Cell Mol Life Sci 2008, 65(17):2688-2701

16. Sanchez AM, Candau RB, Csibi A, Raibon A, et al: The role of AMP-activated protein kinase in the coordination of skeletal muscle turnover and energy homeostasis. Am J Physiol Cell Physiol 2012, 303(5):C475-485.

17. Long YC, Cheng Z, Copps KD, White MF: Insulin receptor substrates Irs 1 and Irs2 coordinate skeletal muscle growth and metabolism via the Akt and AMPK pathways. Mol Cell Biol 2011, 31(3):430-441.

18. Tong JF, Yan X, Zhu MJ, Du M: AMP-activated protein kinase enhances the expression of muscle-specific ubiquitin ligases despite its activation of IGF-1/Akt signaling in C2C12 myotubes. J Cell Biochem 2009, 108(2):458-468. 
19. McPherron AC, Lawler AM, Lee SJ: Regulation of skeletal muscle mass in mice by a new TGF-beta superfamily member. Nature 1997, 387(6628):83-90

20. Sartorelli V, Fulco M: Molecular and cellular determinants of skeletal muscle atrophy and hypertrophy. SCi STKE 2004, 244:re11.

21. Otto A, Patel K: Signalling and the control of skeletal muscle size. Exp Cell Res 2010, 316(18):3059-3066.

22. Nader GA: Molecular determinants of skeletal muscle mass: getting the "AKT" together. Int J Biochem Cell Biol 2005, 37(10):1985-1996.

23. Sandri M: Signaling in muscle atrophy and hypertrophy. Physiology (Bethesda) 2008, 23:160-170.

24. Glass DJ: Skeletal muscle hypertrophy and atrophy signaling pathways. Int J Biochem Cell Biol 2005, 37(10):1974-1984.

25. Heron-Milhavet L, Franckhauser C, Rana V, Berthenet C, Fisher D, et al: Only Akt1 is required for proliferation, while Akt2 promotes cell cycle exit through p21 binding. Mol Cell Biol 2006, 26:8267-8280.

26. Pervaiz S, Holme AL: Resveratrol: its biologic targets and functional activity. Antioxid Redox Signal 2009, 11(11):2851-2897.

27. Alarcòn de la Lastra C, Villegas I: Resveratrol as an antioxidant and pro-oxidant agent: mechanisms and clinical implications. Biochem SoC Trans 2007, 35:1156-1160.

28. Szkudelska K, Szkudelski T: Resveratrol, obesity and diabetes. Eur J Pharmacol 2010, 635:1-8.

29. Francine Z, Marques M, Markus MA, Morris BJ: Resveratrol: cellular actions of a potent natural chemical that confers a diversity of health benefits. Int $J$ Biochem Cell Biol 2009, 41(11):2125-2128.

30. Das S, Fraga CG, Das DK: Cardioprotective effect of resveratrol via HO-1 expression involves p38 map kinase and Pl-3-kinase signaling, but does not involve NFKappaB. Free Radic Res 2006, 40:066-1075.

31. Sulaiman M, Matta MJ, Sunderesan NR, Gupta MP, Periasamy M, Gupta M: Resveratrol, an activator of SIRT1, upregulates sarcoplasmic calcium ATPase and improves cardiac function in diabetic cardiomyopathy. Am J Physiol Heart Circ Physiol 2010, 298(3):H833-H843.

32. Shen $M$, Wu RX, Zhao L, Li J, Guo HT, Fan R, et al: Resveratrol attenuates ischemia/reperfusion injury in neonatal cardiomyocytes and its underlying mechanism. PLoS One 2012, 7(12):e51223.

33. Juhasz B, Varga B, Gesztelyi R, Kemeny-Beke A, Zsuga J, Tosaki A: Resveratrol: a multifunctional cytoprotective molecule. Curr Pharm Biotechnol 2010, 11(8):810-818.

34. Zhu X, Liu Q, Wang M, Liang M, Yang X, Xu X, Zou H, Qiu J: Activation of Sirt1 by resveratrol inhibits TNF-a induced inflammation in fibroblasts. PLoS One 2011, 6(11):e27081.

35. Szkudelski T, Szkudelska K: Anti-diabetic effects of resveratrol. Ann N Y Acad Sci 2011, 1215:34-39.

36. Shakibaei M, Shayan P, Busch F, Aldinger C, Buhrmann C, Lueders C, Mobasheri A: Resveratrol mediated modulation of Sirt-1/Runx2 promotes osteogenic differentiation of mesenchymal stem cells: potential role of Runx2 deacetylation. PLoS One 2012, 7(4):e35712.

37. Do GM, Jung UJ, Park HJ, Kwon EY, Jeon SM, McGregor RA, Choi MS: Resveratrol ameliorates diabetes-related metabolic changes via activation of AMP-activated protein kinase and its downstream targets in $\mathrm{db}$ db mice. Mol Nutr Food Res 2012, 56(8):1282-1291.

38. Brasnyó P, Molnár GA, Mohás M, Markó L, Laczy B, et al: Resveratrol improves insulin sensitivity, reduces oxidative stress and activates the Akt pathway in type 2 diabetic patients. Br J Nutr 2011, 106(3):383-389.

39. Hwang JT, Kwon DY, Park OJ, Kim MS: Resveratrol protects ROS-induced cell death by activating AMPK in H9c2 cardiac muscle cells. Genes Nutr 2008, 2(4):323-326

40. Lagouge M, Argmann C, Gerhart-Hines Z, et al: Resveratrol improves mitochondrial function and protects against metabolic disease by activating SIRT1 and PGC-1a. Cell 2006, 127(6):1109-1122.

41. Dirks Naylor AJ: Cellular effects of resveratrol in skeletal muscle. Life Sc 2009, 84:637-640.

42. Park CE, Kim MJ, Lee JH, Min Bl, et al: Resveratrol stimulates glucose transport in $\mathrm{C} 2 \mathrm{C} 12$ myotubes by activating AMP-activated protein kinase. Exp Mol Med 2007, 39(2):222-229.

43. Alamdari N, Aversa Z, Castillero E, Gurav A, Petkova V, Tizio S, Hasselgren PO: Resveratrol prevents dexamethasone-induced expression of the muscle atrophy-related ubiquitin ligases atrogin-1 and MuRF1 in cultured myotubes through a SIRT1-dependent mechanism. Biochem Biophys Res Commun 2012, 417(1):528-533.
44. Kim HJ, Kim IK, Song W, Lee J, Park S: The synergic effect of regular exercise and resveratrol on kainate-induced oxidative stress and seizure activity in mice. Neurochem Res 2013, 38(1):117-122.

45. Menzies KJ, Singh K, Saleem A, Hood DA: Sirtuin 1-mediated effects of exercise and resveratrol on mitochondrial biogenesis. $J$ Biol Chem 2013, 288(10):6968-6979.

46. Kaminski J, Lançon A, Aires V, Limagne $E$, et al: Resveratrol initiates differentiation of mouse skeletal muscle-derived C2C12 myoblasts. Biochem Pharmacol 2012, 84(10):1251-1259.

47. Burattini S, Ferri $P$, Battistelli M, Curci R, et al: C2C12 murine myoblasts as a model of skeletal muscle development: morpho-functional characterization. Eur J Histochem 2004, 48(3):223-233.

48. Yaffe D, Saxel O: Serial passaging and differentiation of myogenic cells isolated from dystrophic mouse muscle. Nature 1977, 270:725-727.

49. Sharples AP, Al-Shanti N, Stewart CE: C2 and C2C12 murine skeletal myoblast models of atrophic and hypertrophic potential: relevance to disease and ageing? J Cell Physiol 2010, 225(1):240-250.

50. Sharples AP, Stewart CE: Myoblast models of skeletal muscle hypertrophy and atrophy. Curr Opin Clin Nutr Metab Care 2011, 14(3):230-236.

51. Senesi P, Luzi L, Montesano A, Mazzocchi N, Terruzzi I: Betaine supplement enhances skeletal muscle differentiation in murine myoblasts via IGF-1 signaling activation. J Trans/ Med 2013, $11(1): 174$

52. Montesano A, Luzi L, Senesi P, Terruzzi I: Modulation of cell cycle progression by 5 -azacytidine is associated with early myogenesis induction in murine myoblasts. Int J Biol Sci 2013, 9(4):391-402.

53. Terruzzi I, Senesi P, Magni C, Montesano A, et al: Insulin-mimetic action of Conglutin- $\gamma$, a lupin seed protein, in mouse myoblasts. Nutr Metab Cardiovasc Dis 2010, 21(3):197-205.

54. Gotz C, Montenarh M: p53 and its implication in apoptosis (review). Int J Oncol 1995, 6(5):1129-1135.

55. Figliola R, Maione R: MyoD induces the expression of p57Kip2 in cells lacking p21Cip1/Waf1: overlapping and distinct functions of the two cdk inhibitors. J Cell Physiol 2004, 200(3):468-475.

56. Halevy O, Novitch BG, Spicer DB, Skapek SX: Correlation of terminal cell cycle arrest of skeletal muscle with induction of p21 by MyoD. Science 1995, 267(5200):1018-1021.

57. Jansen KM, Pavlath GK: Molecular control of mammalian myoblast fusion. Methods Mol Biol 2008, 475:115-133.

58. Rochlin K, Yu S, Roy S, Baylies MK: Myoblast fusion: when it takes more to make one. Dev Biol 2010, 341(1):66-83.

59. Tanaka K, Sato K, Yoshida T, Fukuda T, et al: Evidence for cell density affecting $\mathrm{C} 2 \mathrm{C} 12$ myogenesis: possible regulation of myogenesis by cellcell communication. Muscle Nerve 2011, 44(6):968-977.

60. Knudsen KA, Myers L, McElwee SA: A role for the Ca2(+)-dependent adhesion molecule, $\mathrm{N}$-cadherin, in myoblast interaction during myogenesis. Exp Cell Res 1990, 188(2):175-184

61. Rommel C, Bodine SC, Clarke BA, Rossman R, et al: Mediation of IGF-1-induced skeletal myotube hypertrophy by $\mathrm{PI}(3) \mathrm{K} / \mathrm{Akt} / \mathrm{mTOR}$ and PI(3)K/Akt/GSK3 pathways. Nat Cell Biol 2001, 3(11):1009-1013.

62. Coolican SA, Samuel DS, Ewton DZ, McWade FJ, Florini JR: The mitogenic and myogenic actions of insulin-like growth factors utilize distinct signaling pathways. J Biol Chem 1997, 272(10):6653-6662.

63. Metzger T, Gache V, Xu M, Cadot B, et al: MAP and kinesin-dependent nuclear positioning is required for skeletal muscle function. Nature 2012, 484(7392):120-124

64. Li J, Johnson SE: ERK2 is required for efficient terminal differentiation of skeletal myoblasts. Biochem Biophys Res Commun 2006 345(4):1425-1433.

65. Folker ES, Schulman VK, Baylies MK: Muscle length and myonuclear position are independently regulated by distinct Dynein pathways. Development 2012, 139(20):3827-3837.

66. Buckingham M: How the community effect orchestrates muscle differentiation. Bioessays 2002, 25:13-16.

67. Chargè S, Rudnicki M: Cellular and molecular regulation of muscle regeneration. Physiol Rev 2004, 84(1):209-238.

68. Ye F, Mathur S, Liu M, Borst SE, Walter GA, Sweeney HL, Vandenborne K Overexpression of IGF-1 attenuates skeletal muscle damage and accelerates muscle regeneration and functional recovery after disuse. Exp Physiol 2013, 98(5):1038-1052 
69. Lai KM, Gonzalez M, Poueymirou WT, Kline WO, Na E, et al: Conditional activation of akt in adult skeletal muscle induces rapid hypertrophy. Mol Cell Biol 2004, 24:9295-9304.

70. Poulsen MM, Vestergaard PF, Clasen BF, Radko Y, Christensen LP, et al: High-dose resveratrol supplementation in obese men: an investigator-initiated, randomized, placebo-controlled clinical trial of substrate metabolism, insulin sensitivity, and body composition. Diabetes 2013, 62(4):1186-1195.

doi:10.1186/1479-5876-11-310

Cite this article as: Montesano et al: Resveratrol promotes myogenesis and hypertrophy in murine myoblasts. Journal of Translational Medicine 2013 11:310

\section{Submit your next manuscript to BioMed Central} and take full advantage of:

- Convenient online submission

- Thorough peer review

- No space constraints or color figure charges

- Immediate publication on acceptance

- Inclusion in PubMed, CAS, Scopus and Google Scholar

- Research which is freely available for redistribution 